\title{
Exhaustification, free-choice, and additivity: Evidence from Sakha da(yani)
}

\author{
Ian Kirby*
}

\begin{abstract}
This paper discusses some unique semantic properties displayed by the Sakha quantifier particle da yani (often reduced to $d a$ ). It is shown that, despite significant similarity with well-studied additive TOO-particles such as Japanese -mo and Hungarian is, da(yani) never clearly serves the role of additive too/also/either, nor does it appear in free-choice items. Adopting an exhaustification-based approach wherein quantifier particles activate grammatical alternatives which are in turn interpreted by covert operators $\mathrm{O}(\mathrm{nly})$ or $\mathrm{E}(\mathrm{ven})$, it is proposed that da( yani)marked phrases are typically exhaustified non-recursively.
\end{abstract}

Keywords. Sakha language; Yakut language; negative polarity; alternative semantics; additivity; free-choice; exhaustification; semantics

1. Introduction. Sakha (also known as "Yakut") is a Siberian Turkic language spoken mainly in the Republic of Sakha (Yakutia) in Russia. This language has a unique particle dayani ${ }^{1}$, often reduced to $d a$, which appears in three main environments. First, with WH-words or the numeral biir 'one', it forms negative polarity items (NPIs) (1).
a. $\quad[\operatorname{Kim} \operatorname{da}($ yani) $)]$ biir da kinige-ni $]$ aax-*(pa)-ta
[who $d a] \quad$ [one $d a$ book-ACC] read-(NEG)-PST
'Nobody read any book(s)' (lit: 'Anybody didn't read any book(s)')
b. [Biir da studjen] iti kinige-ni aax-*(pa)-tax
one $d a$ student that book-ACC read-NEG-PST
'No student read that book' (lit: 'Any studend didn't read that book')
c. Min [kim-neejer da(yani)] türgennik süür-d-im
I who-COMPAR da( yani) quickly run-PST-1SG
'I ran faster than anyone'

WH-da( yani) and biir $d a^{2}$ NPIs are grammatical in any position in the scope of negation (1-a)-

\footnotetext{
* I am deeply grateful to my Sakha consultant Daria Boltokova. I would also like to thank Jonathan Bobaljik, Uli Sauerland, Dora Mihoc, Niels Kühlert, Gunnar Lund, Tamisha Tan, and Tamás Halm, Gennaro Chierchia, audiences at the 5th Workshop on Turkic and languages in contact with Turkic (Tu+5), 95th Annual Meeting of the Linguistics Society of America, and many others. Author: Ian Kirby, Harvard University (ikirby@g.harvard.edu).

${ }^{1}$ The native Cyrillic orthography is <дақаны>. In this paper I adopt a phonemic transcription of da yani. [в] is an of allophone $/ \mathrm{\gamma} /$ and the particle is rendered as [даваni]. The particle has variously been romanized dayanı (Krueger 1962: 115), da yanï (Stachowski \& Menz 1998: 423), and daqany (Vinokurova 2005; Baker \& Vinokurova 2010), among others. Transcriptions from native speakers tend to use $<\mathrm{gh}>$ for $[\mathrm{y}] \sim[\mathrm{b}]$, and $<\mathrm{kh}>$ for $[\mathrm{x}, \chi]$ (as in $S a k h a$ [saxa]), though $\langle\mathrm{x}>$ is used as well for these phones, as it is consistent with the native script $<\mathrm{x}>$. While I adopt

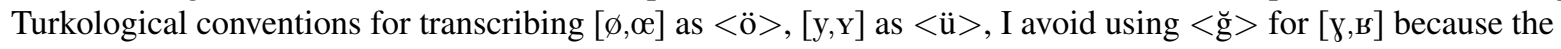
former is typically used for reflexes of Proto-Turkic $* g$, while Sakha $[\mathrm{\gamma}, \mathrm{\textrm {L }}]$ is a reflex of Proto-Turkic $* k$.

2 The factors governing the alternation between full dayani and reduced $d a$ are complex and poorly understood, though they have been noted since the earliest descriptive work on Sakha (i.e. Böhtlingk 1964 [1851]: §670). I have found no evidence that it is decomposable into two or more morphemes, hence dubbing the alternation "reduction". In general, whenever the full form is acceptable, the reduced form is as well, but not vice versa: When the host is an NP, the particle appears NP-final with bare NPs (i.e. no quantificational determiner), where reduction is optional (e.g. kim da( yani) in (1), kinige da (yani) in (2-a)); when the host NP has a determiner, da invariantly appears in the second position of the NP (immediately following the determiner), and reduced $d a$ is preferred (e.g. biir da in (1), elbex da in (2-b)).
} 
(1-b), and are ungrammatical if such a licenser is absent, a hallmark of NPIs. The standard of comparison like (1-c), where kim 'who' is inflected for comparative case, is an additional licensing environment of these NPIs.

$D a$ (yani)'s second main use is in focused environments (2).
a. $\quad[($ Onnooyor) studjen da(yani) $]$ iti kinige-ni aax-(pa)-ta
(even) student $d a$ (yani) that book-ACC read-(NEG)-PST
'Even A/THE STUDENT read/didn't read that book!'
b. [Elbex da kihi] kinige aax-(pa)-ta
many $d a$ people book read-(NEG)-PST
'So many people read/didn't read the book'

When $d a$ (yani)'s host is focused (2), the resulting meaning is that something about the host is unexpected or surprising. For example, (2-a) is only felicitous if it is contextually expected that the student is the least likely alternative in the discourse to read (or not read) the book. In (2-b), $d a$ is used as an intensifier, expressing that the amount of people reading that book (or not reading it) is unexpected. Unlike when da(yani) marks a WH-word or biir 'one' (1), $d a($ yani) can mark focused elements in both positive and negative sentences.

Finally, $d a$ (yani) can be doubled, marking each member of a coordination (3). If the polarity of the sentence is positive, this resolves to a 'both...and' meaning (3-a), while negatives resolve to a narrow-scope disjunction 'neither...nor' reading (3-b).

Djulus [kofje da(yani)] [čaj da(yani)] is-(pe)-te

D. coffee $d a$ (yani) tea $d a$ (yani) drink-(NEG)-PST

a. Positive (without -pe-): 'Djulus drank both coffee and tea'

b. Negative (with -pe-): 'Djulus drank neither coffee nor tea' / 'Djulus didn't drink coffee or tea'

In coordinations like (3), both instance of the particle are obligatory, though mismatches where one instance is full dayani and the other reduced $d a$ are almost always acceptable. There is a strict requirement that the phrases $d a$ (yani) appears to the right of have the same syntactic label (see Vinokurova 2005: 202).

In recent years, the semantic contribution of quantifier particles has been a topic of great interest in the literature (see Szabolcsi 2015 et seq., Mitrović 2021). Szabolcsi (ibid: 161) summarizes three basic questions they raise for semantic compositionality.

(4) a. "Do the roles of each particle form a natural class with a stable semantics?"

b. "Are the particles aided by additional elements, overt or covert, in fulfilling their varied roles? If yes, what are those elements?"

c. "What do we make of the cross-linguistic similarities in the distribution and interpretation of the particles?"

The theoretical backdrop of this paper is that, for Sakha da(yani) and other quantifier particles, the answer to (4-a) is "yes". For question (4-b) it is assumed-adopting an exhaustificationbased view of NPIs (Chierchia 2013) — that da(yani)-marked elements have active alternatives, and that these activated alternatives are interpreted by covert exhaustifiers.

It is question (4-c) that this paper seeks to engage with most directly, as Sakha da(yani)'s distribution is unique. In $\S 2$, I compare $d a($ yani) to two well-studied quantifier particles- 
Hungarian is/sem and Japanese -mo. These form a constellation of meanings commonly captured under the descriptive labels of TOO- or MO-particles (Szabolcsi 2015, 2017). It is shown that Sakha $d a$ (yani)'s roles form a subset of those of Japanese -mo and Hungarian is/sem, in that $d a$ (yani) does not appear in free-choice items (FCIs) or as an additive focus particle. The latter, i.e. the observation that $d a$ (yani) largely behaves like a TOO-particle, yet never clearly functions as plain additive too, is the most surprising-in effect, it appears that $d a$ (yani) is a TOO-particle that lacks a basic 'too/also' meaning.

$\$ 3$ briefly provides an analysis of $d a($ yani) in NPIs and focus. It is argued that the particle activates its host's alternatives, making them obligatory (i.e. not subject to Gricean relevance). When the host is a low-point of scale existential like a WH-word or biir 'one', this creates NPIs. When the host is a focused element, it is only interpretable if the focus alternatives are ranked along a probability scale with the $d a$ (yani)-marked alternative being the scale's lowest member.

$\S 4$ brings recursive exhaustification in, arguing that $d a($ yani)-coordination is underlying a disjunction, and that $d a$ (yani) marks each disjunct's alternatives as obligatorily active. The entire disjunct is recursively exhaustified (with no scalar alternative), routinely strengthening or to and in positive sentences. This section explores further why da(yani) does not appear in FCIs (commonly argued to be the result of recursive exhaustification), or as an additive too particle. I argue that this is because a single instance of $d a($ yani) does not trigger recursive exhaustification, and explore a proposal from Szabolcsi (2017) to derive the additive presupposition through recursive exhaustification, an operation $d a($ yani) apparently does not induce. $\$ 5$ concludes the paper.

2. Distribution and crosslinguistic parallels. The well-known Japanese particles $-m o$ and $-k a$ serve as the starting point for most analyses of quantifier particles (Szabolcsi 2015; Mitrović 2021). Of these, -mo is the relevant comparandum for our purposes. While -mo appears in an exceptionally wide distribution of environments, many of these roles overlap considerably with quantifier particles in other languages, such as Hungarian is (negative concord: sem), forming a group often called TOO- or MO-particles. The main uses of Sakha $d a($ yani), Hungarian is/sem, and Japanese -mo are shown in Table 1.

\begin{tabular}{|c|c|c|c|}
\hline Role & Sakha da(yani) & Hungarian is/sem & Japanese $-m o$ \\
\hline NPI, anybody & $\checkmark$, kim $\mathbf{d a}$ & $\begin{array}{l}\checkmark, \text { valaki is, akárki } \\
\text { is, senki }\end{array}$ & $\checkmark$, dare-mo \\
\hline even $\mathrm{X}$ & $\checkmark$, (onnoо уог) X da & $\checkmark$, még $\mathrm{X}$ is & $\checkmark, \mathrm{X}-\mathrm{mo}$ \\
\hline both $\mathrm{X}$ and $\mathrm{Y}$ & $\checkmark, \mathrm{X} d a \mathrm{Y} d a$ & $\checkmark, \mathrm{X}$ is $\mathrm{Y}$ is & $\checkmark$, X-mo Y-mo \\
\hline neither X nor Y & $\checkmark, \mathrm{X} d a \mathrm{Y} d a$ & $\begin{array}{l}\checkmark, X \text { sem } Y \text { sem, } \\
\text { sem } X \text { sem } Y\end{array}$ & $\checkmark$, X-mo Y -mo \\
\hline X tooleither & $x$ & $\checkmark, X$ is,$X$ sem & $\checkmark, \mathrm{X}-\boldsymbol{m o}$ \\
\hline FCI, anybody/whoever & $x$ & $\checkmark$, akárki is, bárki is & $\checkmark$, dare-de-mo \\
\hline$\forall$-GQ, everyone & $x$ & $x$ & $\checkmark$, daré-mo \\
\hline
\end{tabular}

Table 1. Main distribution of Sakha da (yani) (here shortened to da for reasons of space), Hungarian is/sem (Kiss 2004; Szabolcsi 2015, 2017, 2018; Halm 2016), and Japanese -mo (Shimoyama 2006, 2011; Nakanishi 2006; Kobuchi-Philip 2009) 
As Table 1 shows, Sakha da (yani) performs fewer roles than Hungarian is/sem or Japanese -mo. The most surprising absence for a candidate TOO-particle is the $\mathrm{X}$ too/either function. ${ }^{3}$ The standard analysis of elements like English too is that they are additive focus particles (Rullmann 2003) - that is, they carry a presupposition that, in addition to the ordinary value of the sentence, at least one member of the focus alternative is true. This is shown in (5-a) for Hungarian is, corresponding to English too/also, and (5-b) for sem, corresponding to English post-focal either.

(5) Hungarian (Szabolcsi 2017)

a. BILL is ásított

B. is yawn.PST

'BILL yawned, too'

(i) Ordinary value $=$ Bill yawned

(ii) Focus value $=$ Bill yawned, Katalin yawned, Mari yawned

(iii) Presupposition: Katalin yawned or Mari yawned / somebody other than Bill yawned.

b. BILL sem ásított

Bill sem yawn.PST

'Bill didn't yawn, either'

(i) Ordinary value $=$ Bill didn't yawn.

(ii) Focus value = Bill didn't yawn, Katalin didn't yawn, Mari didn't yawn

(iii) Presupposition: Katalin didn't yawn or Mari didn't yawn / somebody other than Bill didn't yawn.

Sakha $d a$ (yani) is infelicitous in these contexts. ${ }^{4}$ Instead, a particle emie is used (6).

(6) Djulus $\{\#$ da(yani) / emie $\}$ kofje is-(pe)-te

Djulus $\{d a$ (yani) / also $\}$ coffee drink-(NEG)-PST

a. Positive: 'DJULUS drank coffee, too'

b. Negative: 'DJULUS didn't drink coffee, either'

With $d a$ ( yani), sentence (6) can only have a scalar focus even reading. To reiterate, this suggests that it is a TOO-particle which never means 'too'. To my knowledge, no other language

\footnotetext{
${ }^{3}$ Note that non-appearance in FCIs is observed in other TOO-particles, e.g. Bosnian/Serbian/Croatian $i$ (negative concord $n i$ ) (Kirby 2020). There are many additional intriguing and important aspects that I omit here, such as the licensing environments of the NPIs in Table 1, which I discuss in Kirby 2021.

4 Of note is that $d a$ and dayani are often translated as 'also' (e.g. Böhtlingk 1964 [1851]: §670; Krueger 1962: 115; Straughn 2006; Landmann 2016: 108, 136). It is not clear to me whether there are indeed dialects which would use the particle that way, or if this is a result of assumptions from comparative Turkic languages (as many other Turkic languages use $d a$ (yani)'s cognate as an additive particle, e.g. Turkish $d A$ (Kornfilt 1997: 109-10)). None of the above reference provide a clear example where the particle functions like also. One potential example comes from the online Sakha-Russian dictionary sakhatyla.ru which supplies Russian tozhe as a translation, providing (i) as an example translated to Russian (ii).

(i) Sakha

Min da bil-er et-im I $d a$ know-PRES AUX-1SG

(ii) Russian

$$
\begin{array}{lll}
\text { Ja tozhe } & \text { znal } \\
\text { I } & \text { also } & \text { know.IMPFV.MASC.SG }
\end{array}
$$$$
\text { 'I also knew' }
$$

My consultant rejected (ii) as a translation for (i), instead reporting that (i) means 'Even I knew'. It is quite possible that there is dialectal variation, though in at least some dialects of Sakha, the particle resists uses as additive too/also.
} 
is claimed to have a particle with such a distribution, making $d a$ (yani) unique, though it is exceedingly likely that this pattern is yet-to-be identified in other languages. In the rest of this paper, I explore how the semantics of such a particle can be accounted for.

3. Quantifier particles and (non-recursive) exhaustification of alternatives. $D a$ ( yani)'s NPI and scalar focus role can be readily accounted for within Chierchia's (2013, see ch. 3 in particular) Grammatical Theory of Polarity sensitivity. This theory analyzes NPIs as existentials with active alternatives, similar to ordinary scalar implicatures (e.g. the disjunctive reading of English or in positive, episodic sentences with regular intonation). Unlike ordinary scalars, the alternatives of NPIs are obligatory. Both the obligatory alternatives of NPIs and the nonobligatory alternatives of ordinary scalars must be exhaustified. Exhaustifiers take a proposition which has active alternatives and asserts the ordinary value of the statement (the "prejacent") and returns an interpretable LF only if a) the prejacent proposition is true and b) the alternatives have appropriate logical shape to satisfy their exhaustifier. The difference between nonobligatory and obligatory alternatives is that, if exhaustification contradicts the prejacent, ordinary scalars can ignore (or "prune") the contradictory alternatives, while elements with obligatory alternatives cannot. If a contradiction emerges for the latter, it results in uninterpretability and thus is ungrammatical.

There are two main exhaustifiers, O (7), and E. O is a covert version of only: ${ }^{5}$

$\mathrm{O}_{\mathrm{ALT}}(\phi)=[\phi=\mathrm{T}]$ and for all $\psi$ in the alternative set of $\phi$ :

a. if $\phi$ entails $\psi$, then $[\psi=\mathrm{T}]$

b. if $\phi$ does not entail $\psi$, then $[\psi=\mathrm{F}]$ (i.e. $[\neg \psi=\mathrm{T}]$ )

$\mathrm{O}$ applied to a proposition with active alternatives $\phi$ is satisfied only if negating all of it's nonentailed alternatives does not contradict $\phi$.

The E-exhaustifier is a covert version of even (8):

$\mathrm{E}_{\mathrm{ALT}}(\phi)=[\phi=\mathrm{T}]$ and for all $\psi$ in the alternative set of $\phi,\left[\phi<_{\mu} \psi\right]$

In (8) ' $\phi,\left[\phi<_{\mu} \psi\right]$ ' says that the prejacent proposition $\phi$ is ranked lower on a probability scale $\mu$ than any $\psi$ in its alternative set. If any member of $\phi$ 's alternative set $\operatorname{ALT}(\phi)$ is less likely than $\phi$, then $\mathrm{E}_{\mathrm{ALT}}(\phi)$ is uninterpretable. Note that from now on, I will not be including the subscript ALT for exhaustifiers.

The choice between $\mathrm{O}$ and $\mathrm{E}$ is determined by the nature of the alternatives, in particular the scalar alternative. If the scalar is a conjunction of all of the domain alternatives (e.g. if the proposition is $(p \vee q)$ and the scalar alternative is $(p \wedge q)$ ), then $O$ is appropriate. If the alternatives are a rich scale, whether totally ordered by entailment (e.g. numerals), or pragmatically ranked by the context, then $\mathrm{E}$ is appropriate. ${ }^{6}$

To briefly show this theory in practice as it relates to $d a$ (yani), first consider a WH-da(yani) NPI formed from tuox 'what' (9).

$$
\begin{aligned}
& \text { Min tugu da(yani) aax-*(pa)-t-im } \\
& \text { I what.ACC da(yani) read-(NEG)-PST-1SG } \\
& \text { 'I didn't read anything' }
\end{aligned}
$$

\footnotetext{
${ }^{5} \mathrm{O}$ is Chierchia's (2013) convention. It is largely the same as exh used elsewhere (e.g. Fox 2007; Chierchia et al. 2008).

${ }^{6}$ Chierchia (2013) formalizes this as a grammatical principle called OPTIMAL FIT (see pp. 147-58).
} 
Ultimately, the meaning of the negative version of (9) after exhaustification is a negation scoping over an existential: $\neg \exists \mathrm{x}[\operatorname{thing}(\mathrm{x}) \wedge \operatorname{read}(\mathrm{I}, \mathrm{x})]$. The reason that the positive version of (9) is bad is that exhaustifying the NPI's alternatives creates problems. As WH-words are existentials, we can define tugu da(yani) as in (10).

$$
\llbracket \text { tugu da }(\mathrm{yani}) \rrbracket=\llbracket \text { anything }_{\mathrm{NPI}} \rrbracket=\lambda \mathrm{P}_{\langle\mathrm{e}, \mathrm{t}\rangle} \cdot \lambda \mathrm{Q}_{\langle\mathrm{e}, \mathrm{t}\rangle} \cdot \exists \mathrm{x} \in \mathrm{D}_{\mathrm{e}}[\operatorname{thing}(\mathrm{x}) \wedge \mathrm{Q}(\mathrm{x})]_{[+\mathrm{ALT}]}
$$

The subscripted $[+\mathrm{ALT}]$ in (10) is meant to signify that this sequent has obligatorily active alternatives. For clarity, let us restrict the domain to two members: $a$ and $b$. Thus, I read something applied to this domain can be translated to propositional logic $(p \vee q)$, where $p=$ 'I read a' and $q=$ 'I read b'. The individual disjuncts $p$ and $q$ are a type of alternative known as subdomain alternatives (Sauerland 2004). The full set of alternatives is the union of the domain alternatives and the scalar alternative (here $(p \wedge q)$ ), shown in (11) for $(p \vee q)(9)$ :

$$
\operatorname{ALT}(\mathrm{p} \vee \mathrm{q})=\{\mathrm{p} \vee \mathrm{q}, \mathrm{p}, \mathrm{q}, \mathrm{p} \wedge \mathrm{q}\}
$$

Of these alternatives (11), the prejacent ( $p \vee q)$ entails only $(p \vee q)$-none of the rest are entailed. Because tugu da ( yani) has active alternatives, we must exhaustify. For a set of alternatives like (11), O (7) is the appropriate exhaustifier. The result of exhaustifying this positive sentence is shown in (12):

$$
\mathrm{O}(\mathrm{p} \vee \mathrm{q})=(\mathrm{p} \vee \mathrm{q}) \wedge \underbrace{\neg \mathrm{p} \wedge \neg \mathrm{q}}_{\neg(\mathrm{p} \vee \mathrm{q})} \wedge \neg(\mathrm{p} \wedge \mathrm{q})
$$

In (12), $\mathrm{O}(\mathrm{p} \vee \mathrm{q})$ asserts the prejacent $(\mathrm{p} \vee \mathrm{q})$ and negates all the non-entailed alternatives. As the underbrace below the negated domain alternatives shows, this contradicts the prejacentthe resulting sequent is true in no possible world. ${ }^{7}$ Hence, this LF is uninterpretable. On Chierchia's (2013) approach, this contradiction is the source of an NPI's ungrammaticality in positive sentences.

For the negative version of (9), exhaustification does not produce a contradiction. This is because negation also negates alternatives (13-a) and this reverses the entailment relationshipsi.e. $\neg(\mathrm{p} \vee \mathrm{q})$ now entails all its alternatives.

【negative version of $(9) \rrbracket=\neg \exists \mathrm{x} \in \mathrm{D}_{\mathrm{e}}\left[\operatorname{thing}(\mathrm{x} \wedge \operatorname{read}(\mathrm{I}, \mathrm{x})]_{[+\mathrm{ALT}]} \equiv \neg(\mathrm{p} \vee \mathrm{q})\right.$

a. $\operatorname{ALT}(\neg(\mathrm{p} \vee \mathrm{q}))=\{\neg(\mathrm{p} \vee \mathrm{q}), \neg \mathrm{p}, \neg \mathrm{q}, \neg(\mathrm{p} \wedge \mathrm{q})\}$

b. $\mathrm{O}(\neg(\mathrm{p} \vee \mathrm{q}))=\neg(\mathrm{p} \vee \mathrm{q}) \wedge \neg \mathrm{p} \wedge \neg \mathrm{q} \wedge \neg(\mathrm{p} \wedge \mathrm{q})$

Because all of the alternatives are entailed (13-a), O does not negate anything. Instead it simply asserts the same set of alternatives (13-b). This is how the NPI-effect is derived from exhaustification. 8

E-exhaustification is necessary to capture the semantics of biir da NPIs and da(yani)'s scalar focus reading, because the scalar alternatives here are not simply the conjunction of the domain alternatives. For numerals like biir, the alternative set is the scale of positive natural numbers, while even-focus has a set of focus alternatives ordered along a pragmatic probability

\footnotetext{
${ }^{7}$ Again, if the alternatives were not obligatory, this contradiction could be ignored, producing exclusive disjunction: $(\mathrm{p} \vee \mathrm{q}) \wedge \neg(\mathrm{p} \wedge \mathrm{q})$.

${ }^{8} \mathrm{~A}$ brief note about the licensing of $d a($ yani) in comparatives (1-c) - many proposals for the semantics of comparatives include a covert negation (e.g. Gajewski 2008). Hence, this can be captured similarly to licensing via overt negation.
} 
scale. For brevity, I will show only the latter here (see Chierchia 2013: 155-8, Crnič 2014 on numeral-based NPIs).

For even-focus $d a(y a n \dot{i})$, the particle is grammatical in both positive and negative sentences (14). A toy set of alternatives is shown in (14-a) for the positive version, (14-b) for the negative.

$[($ Onnooyor) studjen da(yani) $]$ iti kinige-ni aax-(pa)-ta

(even) student $d a$ (yani) that book-ACC read-(NEG)-PST

'Even the student read/didn't read that book'

a. (i) Prejacent/ordinary value: $\{$ The student read that book\}

(ii) Focus alternatives: \{ The student read that book, the teacher read that book, the headmaster read that book\}

b. (i) Prejacent/ordinary value: $\{$ The student didn't read that book $\}$

(ii) Focus alternatives: \{The student didn't read that book, the teacher didn't read that book, the headmaster didn't read that book

The final ingredient for E-exhaustification is that the focus alternatives (14-a-ii), (14-b-ii) are ranked along a probability scale. For (14), that scale is pragmatically decided based on the contextual likelihood of the student, the teacher, and the headmaster reading the book (or not reading it). Exhaustifying (14) with E is satisfied only if the prejacent is ranked lower than all of the other alternatives on this scale.

(15) Where $\mathrm{p}=$ the student read that book', $\mathrm{q}=$ 'the teacher...', $\mathrm{r}=$ 'the headmaster...'

a. $\mathrm{E}(\mathrm{p})=\mathrm{p} \wedge \forall \psi \in \operatorname{ALT}(\mathrm{p}):\left[\mathrm{p}<_{\mu} \psi\right]$

b. $\quad(15-a)$ is interpretable if and only if $\left(\mathrm{p}<_{\mu} \mathrm{q}\right) \wedge\left(\mathrm{p}<_{\mu} \mathrm{r}\right)$

(15-b) describes the only potential scale that satisfies E-exhaustification of $\mathrm{p}$ - so long as the prejacent $\mathrm{p}$ is less likely than all the other alternatives, the meaning passes through exhaustification. The same reasoning applies under negation (14-b) — no entailment relationship is reversed because none of the focus alternative entail each other in the first place.

A final detail relates to the morphosemantic composition of NPI and particles. The approach sketched above treats $\mathrm{WH}+d a$ (yani) NPIs essentially as idiomatic expressions that are lexically specified to have obligatorily active alternatives, in line with Chierchia's (2013) approach of English any NPIs. A well-noted fact about quantifier particles like da(yani) is that they are not semantically vacuous-without them, the host is not an NPI at all (e.g. in Sakha WH-words are interrogative pronouns, biir is a non-polarity sensitive numeral). Noting that the host of the particles have their own alternatives independent of the particle (i.e. disjunction is inherently an alternative of conjunction, focus induces alternatives), Szabolcsi (2017: 460) proposes that making these already-present alternatives obligatory is one function that these particles serve. I believe the latter is on the right track, because it seems to correctly predict the restricted range of uses that quantifier particles serve-that is, all of the environments they appear in involve alternatives. This will become more relevant in the next section on da(yani) coordination.

4. Recursive exhaustification. Having accounted for for both the NPI and scalar reading of $d a$ (yani) within exhaustification, I now turn to the 'both...and'/'neither...nor' reading of $d a($ yani)...da(yani) coordination, as well as $d a($ yani)'s absence in FCIs and in additive too fo- 
cus. The central tension here is that the 'both...and' reading of $d a$ (yani) coordination resembles the strengthening of a disjunction/existential to a conjunction/universal in the scope of a possibility modal. This is known as the free-choice effect, shown in the English sentence in (16).

Djulus can drink coffee or tea.

a. $\diamond(\mathrm{p} \vee \mathrm{q})=\diamond \mathrm{p} \wedge \diamond \mathrm{q}$

When a possibility modal like can scopes over disjunction, the meaning is strengthened to something conjunction-like. This has been captured within exhaustification by utilizing recursive exhaustification with O (Fox 2007; Chierchia et al. 2008). Recursive exhaustification means that we not only exhaustify the alternatives of the prejacent, but also the alternatives of the alternatives themselves. Chierchia (2013) generalizes this same approach to free-choice items like English any under a possibility modal. The mechanics of recursive exhaustification are shown in $\$ 4.1$.

In the approach to NPIs and scalar-focus $d a$ (yani) in $\S 3$, a critical detail is that the particle's host itself is an existential/disjunction (i.e. an existential like a WH-word or biir 'one', disjunction of focus alternative for emphatic scalar). But when da(yani) appears in a coordinated positive sentence, the resulting meaning is conjunction/universal! There are two details which suggest that this conjunction meaning is not inherent to $d a(y a n i)$...da(yani) coordination. First, under negation (17) (repeated from (3)), it has only one possible scope.

Djulus [kofje da(yani] [čaj da(yani)] is-pe-te

D. coffee $d a$ (yani) tea $d a$ (yani) drink-NEG-PST

a. 'D. didn't drink coffee or tea' / 'D. drank neither coffee nor tea'

$\checkmark \neg(\mathrm{p} \vee \mathrm{q})$

b. \#'D. didn't drink coffee and tea (he drank only one)'

$\boldsymbol{X} \neg(\mathrm{p} \wedge \mathrm{q})$

(17-a) is the only acceptable reading of (17). (17-b), which is compatible with Djulus drinking only coffee or only tea, is completely unavailable. If $d a($ yani)...da(yani) were underlying conjunction, this would be unexpected. Of course, because $\neg(p \vee q)$ is equivalent to $(\neg p \wedge \neg q)$, one could argue that (17-a) is conjunction and that the reason (17) is not scope-ambiguous is because there is an elided negative verb in the left coordinand, an approach which would require no exhaustification to derive the meaning in (17-a).

A second piece of evidence against analyzing $d a$ (yani) coordination as underlying conjunction comes from its pragmatic restrictions. While negative da( yani) coordination like (17) can be used in an out-of-the-blue context, in positive environments its use is pragmatically restricted, and the most common environments that it appears in are environments that are typically identified as exhaustive, such as answers to questions (Dayal 2016). That is, (18-a) is felicitious when it is an answer to a question (whether a WH question like What did Djulus drink? or an alternative question like Did Djulus drink coffee or (did Djulus) drink tea?), while in neutral contexts uonna 'and' (18-b) is used instead.

a. Djulus [kofje da(yani)] [čaj da(yani)] is-te

D. coffee $d a$ (yani) tea da( yani) drink-PST

'Djulus drank both coffee and tea'

b. Djulus kofje uonna čaj is-te

D. coffee and tea drink-PST

'Djulus drank coffee and tea' 
Other than answers to questions, (18-a) is acceptable if only one of the disjuncts is likely to obtain in the context, e.g. if we know that Djulus is sensitive to caffeine and is thus unlikely to drink both coffee and tea, (18-a) would be felicitous. Taken with the unavailability of inverse negation over 'and' readings (17-b), this suggests that on some level da(yani) coordination involves reasoning about semantic alternatives.

In what follows, I outline how to derive the 'both...and' reading via recursive exhaustification $\S 4.1$. Because recursive exhaustification is known to unleash free-choice readings and $d a$ (yani) does not form FCIs, this requires some discussion about why exhaustification is recursive here but not in the case of NPIs or focus. In $\$ 4.2$ it is argued that it is because the particle is repeated in each coordinand that exhaustification is recursive (each alternative is marked as having active alternatives). Finally, $\$ 4.3$ seeks to balance this approach within Szabolcsi's (2017) suggestion that the additive 'too' readings of particles like Hungarian is/sem and Japanese $-m o$ is a product of recursive exhaustification.

4.1. OR-TO-AND STRENGTHENING. The key difference between recursive and non-recursive exhaustification is essentially what level on which exhaustification stops. In $\S 3$, exhaustification only targeted the alternatives of the prejacent. But within the set of alternatives, each individual subdomain alternative has its own set of alternatives which we can pick from the same set of alternatives. This is shown for the alternatives of a disjunction (19), with the alternatives shown in (19-a), (19-b).

$$
\begin{aligned}
& \operatorname{ALT}(p \vee q)=\{p \vee q, p, q, p \wedge q\} \\
& \text { a. } \operatorname{ALT}(p)=\{p, q\} \\
& \text { b. } \operatorname{ALT}(q)=\{p, q\} \\
& \text { c. } \quad \operatorname{ALT}(p \wedge q)=\{p \vee q, p, q, p \wedge q\}
\end{aligned}
$$

Recursive exhaustification is captured by exhaustifying the alternatives in (19-a)-(19-c), as well as the full set of alternatives of $(p \vee q)$ (19). Note that exhaustification of a conjunction like $(p \wedge q)$ is vacuous, because it entails all of the other alternatives in (19-c).

It has been noted that, if the set of alternatives contains only subdomain alternatives (i.e. the scalar is absent), recursive exhaustification will routinely strengthen a disjunction to a conjunction in positive environments (see Szabolcsi 2017: 461). This is shown in (20), where ' $\mathrm{O}$, means "recursively exhaustify".

$$
\begin{aligned}
& \mathrm{O}^{\mathrm{R}}(\mathrm{p} \vee \mathrm{q})=(\mathrm{p} \vee \mathrm{q}) \wedge \neg \mathrm{O}(\mathrm{p}) \wedge \neg \mathrm{O}(\mathrm{q})=\ldots \\
& \text { a. } \quad(\mathrm{p} \vee \mathrm{q}) \wedge \\
& \text { b. } \quad \neg(\mathrm{p} \wedge \neg \mathrm{q}) \wedge \\
& \text { c. } \quad \neg(\mathrm{q} \wedge \neg \mathrm{p})
\end{aligned}
$$

For a subdomain alternative like $p$, the non-entailed alternative is $q$. O negates this (20-b). The negation outside of the parentheses in (20-b) is from the second round of exhaustification (when the prejacent $(p \vee q)$ is exhaustified). Note that $(20-b)$ is equivalent to a material implication $(\mathrm{p} \rightarrow \mathrm{q})$, and similarly for $(20-\mathrm{c}) \neg(\mathrm{q} \wedge \neg \mathrm{p})$ is equivalent to $(\mathrm{q} \rightarrow \mathrm{p})$. Taken together, the exaustified subdomain alternatives entail a biconditional $(p \leftrightarrow q)$. In conjunction with the prejacent $(\mathrm{p} \vee \mathrm{q})$, this means that (20) is only true when $\mathrm{p}=\mathrm{T}$ and $\mathrm{q}=\mathrm{T}$. This is, in effect, how we can strengthen or to and.

There are a few ways that this could be extended to Sakha $d a($ yani)-coordination. Here I 
will sketch just one. As I said in the concluding paragraph of $\S 3$, one possibility is that quantifier particles like $d a$ (yani) themselves are responsible for marking their host's alternatives obligatorily active. Accepting this view, if we view da(yani)-coordination as an underlying disjunction, it would follow that the role of $d a$ (yani) is to activate the alternatives of each disjunct. That is, it marks that each disjunct itself has alternatives that need to be figured into exhaustification. This captures the detail in $\S 1$ that the particle is required in both disjunct. In essence, its role is a morphosyntactic cue that each disjunct needs to be exhaustified.

4.2. (LACK OF) FREE-CHOICE. Omitting the stronger scalar alternative is crucial to the approach in $\$ 4.1$. If it were included, we would reach a contradiction (21).

$$
\mathrm{O}^{\mathrm{R}}(\mathrm{p} \vee \mathrm{q})=(\mathrm{p} \vee \mathrm{q}) \wedge \underbrace{\neg \mathrm{O}(\mathrm{p}) \wedge \neg \mathrm{O}(\mathrm{q})}_{(\mathrm{p} \leftrightarrow \mathrm{q})} \wedge \neg(\mathrm{p} \wedge \mathrm{q})
$$

(21) is always false, hence a contradiction. On the other hand, if there were a possibility modal included in the prejacent, no contradiction would emerge. The resulting formula is shown in (22) (see Chierchia 2013: 187-90 for further details).

$$
\mathrm{O}^{\mathrm{R}}(\diamond(\mathrm{p} \vee \mathrm{q}))=\diamond(\mathrm{p} \vee \mathrm{q}) \wedge(\diamond \mathrm{p} \leftrightarrow \diamond \mathrm{q}) \wedge \neg \diamond(\mathrm{p} \wedge \mathrm{q})
$$

(22) accurately characterizes the meaning of an FCI like English any as used in a sentence like You may pick any card. If there are two cards to choose from, both are acceptable options $(\diamond(\mathrm{p} \vee \mathrm{q}) \wedge(\diamond \mathrm{p} \leftrightarrow \diamond \mathrm{q}))$, but picking both is typically not an acceptable option (hence the negated scalar alternative) ${ }^{9}$

If both subdomain and scalar alternatives are included, a possibility modal prevents recursive exhaustification from producing a contradiction (21). But Sakha da(yani)-coordination does not require a modal to be grammatical, though it is compatible with modals (23):

$$
\begin{aligned}
& \text { Iisus kini-ni ütüördübütüter kihi [körör da] [sayar da] buol-but-a } \\
& \text { Jesus 3SG-ACC cause.to.be.healed person see.PRES } d a \text { speak.PRES } d a \text { become-PTPL-3SG } \\
& \text { 'Jesus healed the man so that he could both speak and see'10 }
\end{aligned}
$$

(23) contains the auxiliary buol- 'be, become', which is interpreted as a future or generic modal when it combines with verbs in the present tense (Landmann 2016: 52-3). So far I have proposed that $d a$ (yani) marks the alternatives of its host obligatorily active, but it is only when it is doubled that these alternatives are recursively exhaustified. If, on the other hand, da(yani) went one step further and forced recursive exhaustification, perhaps by a stipulated diacritic like [+recursive-exh] (or, alternatively, if it were a recursive exhaustifier itself), we would predict that a modal environment like (23) should be grammatical to the exclusion of non-modal sentences like (18-a).

From this line of reasoning, we can explain why $d a$ (yani) does not appear in FCIs - a particle that does so would need to encode that the alternatives need be recursively exhaustified. Because it only activates the alternatives of its host (not the alternatives of the alternatives), $d a($ yani) is ill-suited to form FCIs.

\footnotetext{
${ }^{9}$ I say "typically" here because English any is more accurately a universal FCI (i.e. Anybody can do that is quite similar to everybody can do that). While the exhaustification procedures is the same for universal FCIs, there are additional assumptions to avoid the negated scalar (see Chierchia 2013: ch. 6), details not relevant here.

10 This sentence comes from the Sakha bible, as made available from the Institute for Bible translation (ibtrussia.org).
} 
4.3. (LACK OF) AdDitive TOO REAdings. The final detail I discuss here is the fact that $d a$ (yani) does not serve as a basic additive too, a typologically unique detail ( $\$ 2)$. In addition to the proposal that TOO-particles activate the alternatives of their host (as discussed in $\S 3$ ), Szabolcsi (2017) experiments with a unique approach whereby the additive presupposition of these elements is not inherent to the assertion, but is rather derived through recursive exhaustification. Here I briefly outline this approach and propose that da( yani) is distinct from these TOO-particles in that it does not perform this operation.

Given that particles like is/sem are interpreted by exhaustification in NPIs, FCIs, evenfocus, etc., Szabolcsi (2017) seeks to answer the question of what role exhaustification plays for the additive reading. In essence the goal is to reproduce the set $\operatorname{ALT}^{\mathrm{DIFF}}$ (24-b), which is the set-theoretic difference of the full set of alternatives and the prejacent (24-a), as well as to produce something equivalent to the additive presupposition (24-c), i.e. that in addition to the prejacent, one or more propositions from $\mathrm{ALT}^{\mathrm{DIFF}}$ is true.

(24) BILL is ásított

B. is yawn.PST

'BILL yawned, too'

a. Assertion: yawn $_{\mathrm{w}} *(\mathrm{~b})$

b. $\operatorname{ALT}^{\mathrm{DIFF}}:\left\{\left\{\mathrm{w}: \operatorname{yawn}_{\mathrm{w}}(\mathrm{b})\right\},\left\{\mathrm{w}: \operatorname{yawn}_{\mathrm{W}}(\mathrm{m})\right\},\left\{\mathrm{w}: \operatorname{yawn}_{\mathrm{w}}(\mathrm{k})\right\}\right\} \backslash\left\{\left\{\mathrm{w}: \operatorname{yawn}_{\mathrm{w}}(\mathrm{b})\right\}\right\}$

c. $\quad$ presupposition: $\exists \mathrm{p} \in \mathrm{ALT}^{\mathrm{DIFF}} \cdot\left[\mathrm{p}_{\mathrm{w}} *\right]$ $=\left\{\left\{\mathrm{w}: \operatorname{yawn}_{\mathrm{w}}(\mathrm{m})\right\},\left\{\mathrm{w}: \operatorname{yawn}_{\mathrm{w}}(\mathrm{k})\right\}\right\}$

Szabolcsi's (2017) carries this out by stipulating that, in addition to activating their host's alternatives, TOO-particles go further in "bifurcating" the alternative set (25-a) into two sets: one containing the prejacent, and one containing the disjunction of the other alternatives (25-b).
a. $\quad$ ALT: $\left\{\mathrm{w}: \operatorname{yawn}_{\mathrm{W}}(\mathrm{b}) \vee \operatorname{yawn}_{\mathrm{W}}(\mathrm{m}) \vee \operatorname{yawn}_{\mathrm{W}}(\mathrm{k})\right\}$
b. BI-ALT: $\left\{\left\{\mathrm{w}: \operatorname{yawn}_{\mathrm{W}}(\mathrm{b})\right\},\left\{\mathrm{w}: \operatorname{yawn}_{\mathrm{W}}(\mathrm{m}) \vee \operatorname{yawn}_{\mathrm{W}}(\mathrm{k})\right\}\right\}$

(25-b) equivalent to 'Bill yawned OR Mary or Katalin yawned'. The final assumption is that BI-ALT (25-b) is recursively exhaustified without any stronger scalar alternative. For simplicity, in (26) I represent propositions through the first letters of the subject's name (i.e. ' $b$ ' means w: $\operatorname{yawn}_{\mathrm{w}}(\mathrm{b})$, etc.)

$$
\begin{aligned}
& \mathrm{O}^{\mathrm{R}}(\mathrm{b})=\mathrm{b} \wedge \underbrace{\underbrace{\neg(\mathrm{b} \wedge \neg(\mathrm{m} \vee \mathrm{k}))}_{(\mathrm{b} \rightarrow(\mathrm{m} \vee \mathrm{k}))} \wedge \underbrace{\neg((\mathrm{m} \vee \mathrm{k}) \wedge \neg \mathrm{b})}_{((\mathrm{m} \vee \mathrm{k}) \rightarrow \mathrm{b})}}_{(\mathrm{b} \leftrightarrow(\mathrm{m} \vee \mathrm{k}))} \\
& =\mathrm{b} \wedge(\mathrm{b} \leftrightarrow(\mathrm{m} \vee \mathrm{k}))
\end{aligned}
$$

The result of (26), that Bill yawned is true, and that this is true if and only if Mari or Katilin yawned, is very much akin to an additive presupposition! Szabolcsi concludes that this is the process that such particles undergo to derive their additive reading. If the BI-ALT approach is correct for TOO-particles crosslinguistically, one clear possibility to explain the absence of a basic additive reading of Sakha $d a$ (yani) is that it simply does not bifurcate its alternatives in this way (or at all). In other words, $d a$ (yani) is not a TOO-particle, but shares with them the 
morphosemantic function of encoding the obligatory activation of alternatives. This has a nice benefit of unifying $d a$ (yani)'s absence in FCIs and additive focus-again, because the particle is underspecified for recursive exhaustification, it is ill-suited to appear here.

5. Conclusion. This paper has analyzed data from Sakha $d a$ (yani), concluding that it is an element which marks the alternatives of its hosts as obligatorily active, hence results in the proposition it is embedded within being exhaustified. This particle is typologically unique in that it lacks a basic additive too reading, an absence I argued can be captured if one accepts Szabolcsi's (2017) proposal for deriving additive presuppositions with recursive exhaustification. Because da (yani) only activates the alternatives of its host (not the alternatives of those alternatives), and because it does not bifurcate its alternative set, it does not in-and-of-itself trigger recursive exhaustification. It is only when the particle is embedded in each disjunct of a coordination that it triggers recursive exhaustification, where each disjunct is taken to be an alternative of a larger proposition.

\section{References}

Baker, Mark C. \& Nadya Vinokurova. 2010. Two modalities of case assignment: Case in Sakha. Natural Language \& Linguistic Theory 28. https://doi.org/10.1007/s11049010-9105-1.

Böhtlingk, Otto. 1964 [1851]. Über die Sprache der Jakuten. Indiana University Publications: Uralic and Altaic Series, Vol. 35.

Chierchia, Gennaro. 2013. Logic in grammar: Polarity, free choice, and intervention. Oxford: Oxford University Press. https://doi.org/10.1093/acprof:oso/9780199697977.001.0001.

Chierchia, Gennaro, Danny Fox \& Benjamin Spector. 2008. Scalar implicature as a grammatical phenomenon. In Klaus von Heusinger, Claudia Maienborn \& Paul Portner (eds.), Semantics, 2297-2331. Berlin: de Gruyter. http://dx.doi.org/10.1515/9783110253382.

Crnič, Luka. 2014. Non-monotonicity in NPI licensing. Natural Language Semantics 22. 169217. http://dx.doi.org/10.1007/s11050-014-9104-6.

Dayal, Vaneeta. 2016. Questions. Oxford: Oxford University Press. https://doi.org/10.1093/acprof:oso/9780199281268.001.0001.

Fox, Danny. 2007. Free choice disjunction and the theory of scalar implicatures. In Uli Sauerland \& Penka Stateva (eds.), Presupposition and implicature in compositional semantics, 71-120. London: Palgrove Macmillan. https://doi.org/10.1057/9780230210752_4.

Gajewski, Jon. 2008. More on quantifiers in comparative clauses. Semantics and Linguistic Theory (SALT) 18. 340-357. https://doi.org/10.3765/salt.v18i0.2494.

Halm, Támas. 2016. The grammar offree-choice items in Hungarian: Pázmány Péter Catholic University dissertation. https://doi.org/10.15774/PPKE.BTK.2016.007.

Kirby, Ian. 2020. Sakha da(qany): Negative polarity, conjunction, and focus. Proceedings of the Workshop on Turkic and Languages in Contact with Turkic 5. 71-85. https://doi.org/10.3765/ptu.v5i1.4769.

Kirby, Ian. 2021. Extending the typology of quantifier particles: Sakha da(ghany). Unpublished manuscript. Harvard University.

Kiss, Katalin É. 2004. The syntax of Hungarian. Cambridge, UK: Cambridge University Press. https://doi.org/10.1017/CBO9780511755088.

Kobuchi-Philip, Mana. 2009. Japanese Mo: Universal, additive, and NPI. Journal of Cognitive Science 10. https://doi.org/10.17791/jcs.2009.10.2.173. 
Kornfilt, Jaklin. 1997. Turkish. London: Routledge. https://doi.org/10.4324/9781315823652.

Krueger, John R. 1962. Yakut manual. Bloomington, IN: Indiana University Publications.

Landmann, Angelika. 2016. Jakutisch: Kurzgrammatik. Wiesbaden: Harrassowitz.

Mitrović, Moreno. 2021. Superparticles: A microsemantic theory, typology, and history of logical atoms. Dordrecht: Springer. https://.doi.org/10.1007/978-94-024-2050-0.

Nakanishi, Kimiko. 2006. Even, only, and negative polarity in Japanese. In Masayuki Gibson \& Jonathan Howell (eds.), Proceedings of SALT XVI, 138-155. https://doi.org/10.3765/salt.v16i0.2953.

Rullmann, Hoetze. 2003. Additive particles and polarity. Journal of Semantics 20. 329-401. https://doi.org/10.1093/jos/20.4.329.

Sauerland, Uli. 2004. Scalar implicatures in complex sentences. Linguistics and Philosophy 27. 367-391. https://doi.org/10.1023/b:ling.0000023378.71748.db.

Shimoyama, Junko. 2006. Indeterminate phrase quantification in Japanese. Natural Language Semantics (14). https://doi.org/10.1007/s11050-006-0001-5.

Shimoyama, Junko. 2011. Japanese Indeterminate Negative Polarity Items and their scope. Journal of Semantics 28. https://doi.org/10.1093/jos/ffr004.

Stachowski, Marek \& Astrid Menz. 1998. Yakut. In Lars Johanson \& Éva Ágnes Csató (eds.), The Turkic languages, 417-433. New York: Routledge.

Straughn, Christopher A. 2006. Sakha-English Dictionary (Сахалыы-Англиялыы Тылдьыта). home.uchicago.edu/ straughn/sakhadic.pdf.

Szabolcsi, Anna. 2015. What do quantifier particles do? Linguistics and Philosophy 38. 159204. https://doi.org/10.1007/s10988-015-9166-z.

Szabolcsi, Anna. 2017. Additive presuppositions are derived through activating focus alternatives. In Alexandre Cremers, Thomas van Gessen \& Floris Roelofsen (eds.), Proceedings of the 21 st Amsterdam Colloquium, 455-464. Amsterdam: University of Amsterdam.

Szabolcsi, Anna. 2018. Two types of quantifier particles: Quantifier-phrase internal vs. heads on the clausal spine. Glossa 3(1). 1-32. https://doi.org/10.5334/gjgl.538.

Vinokurova, Nadya. 2005. Lexical categories and argument structure: A study with reference to Sakha. Utrecht, NL: Universiteit Utrecht dissertation. 